\title{
RELAPSING AFTER TREATMENT: EXPLORING THE EXPERIENCES OF CHEMICALLY ADDICTED ADOLESCENTS
}

\author{
Marichen van der Westhuizen, Marianna de Jager
}

\section{INTRODUCTION}

Relapsing after treatment for chemical addiction is common, predictable and preventable, and forms part of the addictive cycle (Buddy, 2003:1; Goodwin, 2000:91-93). Against the background of an increase in the demands for treatment of adolescent chemical addiction, as well as the persistently high relapse rate, the significant impact of chemical addiction on the development and well-being of chemically addicted adolescents needs to be considered by the social work profession, in order to plan effective intervention strategies. The purpose of this research study was to explore and describe the experiences of chemically addicted adolescents who had relapsed after in-patient treatment. Subsequently, the researcher aimed to make recommendations for social workers, in order to prevent relapse.

\section{THEORETICAL BACKGROUND AND RATIONALE}

Adolescent chemical addiction is associated with damaging physical, mental and social health, and interferes with crucial developmental tasks. The lack of development or damage to development in one domain influences the developmental process in the other domains, thus affecting the adolescent's general development (Barrett \& Ollendick, 2004:330; Gouws, Kruger \& Burger, 2000:5; Noyoo, Patel \& Loffell, 2006:97). Therefore, chemical addiction interrupts the general development of adolescents, and impacts on all the life tasks that they have to master. The fact that these life tasks have not been mastered makes efforts to recover from the addiction more difficult, resulting in relapses.

The vulnerability of adolescents to chemical addiction has become a major international concern in recent years. It is associated with a link between drug abuse and HIV and AIDS, as well as a relationship between behavioural problems and drug abuse among adolescents. (Bezuidenhout \& Joubert, 2003:26; Health Systems Trust, 2002; Youth at the United Nations, 2006:1). Approximately 25\% of people in Central Asia and Eastern Europe who inject drugs are under the age of 20 years. In America, one of the most pressing public health concerns remains the persistently high level of substance abuse among adolescents (Barrett \& Ollendick, 2004:329; McWhirter, McWhirter, McWhirter \& McWhirter, 2004:116). Subsequent to the increase in adolescent substance abuse, admissions for treatment in America increased from 28 000 in 1993 to 150000 in 2005. The United Nations and American authorities have identified a definite need for social research regarding the treatment of adolescent substance abuse (Butts \& Roman, 2004:1; Smith, 2006; Youth at the United Nations, 2006:1).

On the local level, drugs are readily available and drug abuse among South African schoolchildren is increasing and undermining the development of South African adolescents. Statistics of the Hospital Association of South Africa reveal that $40 \%$ of adolescents in treatment for chemical addiction suffer from dual diagnosis: addiction as the primary diagnosis and a secondary psychiatric condition. They also point to an increase in the number of young people dying from substance abuse related causes (Gouws et al., 2000:17; Government Gazette, 2002:3; Van Niekerk \& Prins, 2001:38; Zulu, 2006). An analysis by the Drakenstein Police Service of their statistics further indicates that an estimated $80 \%$ of housebreaking- and theft-related cases were drug-related, and most of the arrested suspects were between 12 and 17 
years of age (South African Police Service, 2006). A study conducted by the Medical Research Council during 2005 determined that treatment demands for chemically addicted adolescents in South Africa were also increasing. Regarding the trends in the Western Cape, the aforementioned study indicates that Heroin increased as a primary drug of choice. Methamphetamine, Ecstasy and LSD as the drug of choice were also highest in the Western Cape (South African Community Epidemiology Network on Drug Use, 2005).

Considering the increase in the demands for treatment, an adequate treatment period and ongoing aftercare services are vitally important in preventing adolescent relapse and in ensuring the maintenance of recovery (Gordon, 2003:18; Gorski, 2001:4). Fisher and Harrison (2005:147-148) refer to three different studies in 1997 indicating that different treatment programmes did not have a significant effect on the outcome of treatment. The relapse and recovery rates were, according to these studies, not determined by the treatment programmes, but rather by the quality of the maintenance of recovery.

The importance of the quality of relapse prevention services to chemically addicted adolescents becomes apparent. Although treatment programmes exist and the increase in treatment demands indicates that programmes are being utilised, a high relapse potential still exists (Fisher \& Harrison, 2005:156). Gorski (2001:1) indicates a relapse rate after treatment of 58\% for adolescents.

The aforementioned pressing situation is acknowledged by the White Paper for Social Services of South Africa (1997:43), as well as by the South African Minister of Education (Government Gazette, 2002:7), who emphasises the importance of treatment for adolescent chemical addiction and rehabilitation from drug abuse, as well as the importance of relapse prevention as part of treatment. An extended literature study on the subject of adolescent chemical addiction reveals a wealth of literature that discusses the precipitating factors, as well as relapse prevention models. Previous studies in the field of adolescent chemical addiction include Brandt and Delport (2005:163-174) and Terblanche and Venter (1999:161-178), who investigated the theories and the etiology of adolescent chemical addiction. Although these studies and the literature did not focus on the experiences and needs of the relapsed chemically addicted adolescent, the latter study did identify and evaluate the comfort level with "significant others and preferred helpers".

The following article provides a description of the relapsing experiences of chemically addicted adolescents following treatment and is based on the findings of a qualitative research study. ${ }^{1}$ It is envisaged that social work aftercare services to chemically addicted adolescents will be based on the specific needs, identified by chemically addicted adolescents who have relapsed after treatment, in order to prevent further relapses.

The ensuing sections of this article will focus on the problem statement, followed by a brief discussion of the research methodology employed and descriptions of the key concepts. The demographic details of the participants in this study will be provided, after which the findings will be discussed and compared with the relevant literature. The article will end with concluding remarks and some recommendations to social workers.

\footnotetext{
1 This article is based on a broader research study, conducted for a master's degree at the University of South Africa, completed in 2007.
} 


\section{PROBLEM STATEMENT}

McCoy, Metch and Inciardi (1996:xvi) note that the particular needs of adolescents are often unrecognised and unaddressed when services to chemically addicted adolescents are planned. Aftercare forms an integral part of these services. This research therefore stemmed from the question of how chemically addicted adolescents experience relapsing, in order to address the involvement of the social work profession in this pressing matter.

\section{RESEARCH METHODOLOGY}

The research question flowing from the research problem, as discussed in the previous section, was: What are the experiences of chemically addicted adolescents regarding their relapses following treatment? ${ }^{2}$ This section provides a brief description of the research methodology employed to answer the research question.

The goal of this research was to explore and describe the experiences of chemically addicted adolescents regarding relapsing after treatment, and to make recommendations to assist social workers in rendering effective aftercare services to chemically addicted adolescents.

A qualitative research approach was employed. The primary interest was in the meaning that relapsed adolescents attached to their relapse experiences after treatment (Creswell 2003:181183 ) in order to make recommendations for aftercare services to chemically addicted adolescents in recovery. The researcher described relapsing after treatment, as experienced by chemically addicted adolescents, as objectively as possible (Yegidis \& Weinbach, 1996:93), employing the descriptive research design. Furthermore, exploratory research was employed as the literature and previous studies do not focus on the experiences of chemically addicted adolescents regarding relapsing after treatment, thus indicating a need for further elucidation of the topic (Cherry, 2000:12; Silverman, 2000:9). Employing the contextual research design, the researcher described the events within the immediate, concrete, natural context in which the situation occurred (Babbie \& Mouton, 2001:272). The context shared by the participants in this study was as follows: adolescents suffering from chemical addiction who received in-patient treatment and relapsed thereafter, currently back in in-patient treatment programmes.

The research question guided the decision regarding the population for this study. The total population for this study was thus defined as follows: all chemically addicted adolescents in the Western Cape who had relapsed after in-patient treatment. A representative sample of the population was selected in order to enhance the validity of the study (Walliman, 2001:232). The criteria for inclusion were based on the contextual nature of the research design. The criteria for inclusion in the study were as follows: chemically addicted adolescents who previously underwent in-patient treatment and relapsed thereafter, currently back in in-patient treatment programmes in the Western Cape. Rubin and Babbie (1997:573) advise that participants in interviews be selected on the basis of relevancy to the topic. Purposive sampling was therefore employed to provide the researcher with a sample to access some specialised insights into the phenomena of interest, in this case the experiences of chemically addicted adolescents who had relapsed after treatment. Three treatment centres in the Western Cape participated in the study, and acted as "gatekeepers", regulating the researcher's access to the

2 The research question was directed at chemically addicted adolescents who had received treatment and relapsed thereafter. The conceptual framework is based on the Minnesota Model, which emphasises the addictive cycle, long term treatment and recovery as a lifelong process (Goodwin, 2000:91-93; Gordon, 2003:2). 
participants. The sample size for this study was determined by data saturation, once the information became repetitive (De Vos, Strydom, Fouché \& Delport, 2002:335; Dick, 2000).

The researcher collected the data through 17 semi-structured interviews, and data was recorded by means of transcripts of the interviews and field notes. Tesch's framework for data analysis (in Creswell, 2003) was employed, while data verification was conducted through Guba's model (in Krefting, 1991:214-222) which included triangulation, peer examination, a dense description of the research methodology, and the use of an independent coder.

The limitations to this study were as follows: Social class is not reflected optimally. The participants came from backgrounds where their parents/guardians were unable to afford inpatient treatment. Only Afrikaans- and English-speaking participants from mainly "Coloured" and "White" communities took part in this study, thus not reflecting the experiences of chemically addicted adolescents from other cultures and ethnic groups. However, two of the participants came from the "Black" community, which added value to the data obtained. The majority of participants were male, thus limiting the reflection of the two different genders.

Ethical considerations that guided the research were as follows. Informed consent was obtained by means of consent forms signed by participants, their guardians and the therapists at the treatment centres. Protection from harm to participants was ensured through referrals to the therapists for debriefing after the interviews. The right to privacy and confidentiality of the data was addressed as participants were not forced to share their experiences and were informed that they could withdraw from the interviews at any time. Furthermore, participants were informed that only the researcher, editor and independent coder, as well as the researcher's supervisor and joint supervisor would have access to the tape recordings and transcripts.

The following two sections will describe the key concepts of the research, as well as the demographic details of the participants to the study, and will form the basis for the discussion of the findings.

\section{CLARIFICATION OF KEY CONCEPTS}

Chemical addiction is a condition in which the use of chemical substances causes social, emotional, spiritual and physical impairment. Indicators to be measured are tolerance, progression, withdrawal symptoms, and loss of control (Gossop, 1998:78).

Relapse is a process that occurs within the addict in recovery and manifests itself in a progressive deterioration in the pattern of behaviour and symptoms leading to the use of addictive substances (Gorski \& Miller, 1982:48).

For the purpose of this research, an adolescent was defined as a person between the ages of 11 and 21 years (Louw, Van Eden \& Louw, 2001:385).

Aftercare services are professional social work services to the chemically addicted adolescent in recovery, in order to maintain sobriety (Gorski, 2001:4). 


\section{TABLE 1}

DEMOGRAPHIC DETAILS OF THE PARTICIPANTS TO THE STUDY

\begin{tabular}{|c|c|c|c|c|c|}
\hline AGE & GENDER & LANGUAGE & $\begin{array}{c}\text { DRUG OF } \\
\text { CHOICE }\end{array}$ & $\begin{array}{c}\text { PARENTAL USE OF } \\
\text { CHEMICAL } \\
\text { SUBSTANCES }\end{array}$ & $\begin{array}{l}\text { RACIAL } \\
\text { GROUP }\end{array}$ \\
\hline 18 & Male & Afrikaans & Methamphetamine & No history & Coloured \\
\hline 20 & Male & English & Methamphetamine & Mother: alcohol & Coloured \\
\hline 16 & Male & English & Methamphetamine & No history & Coloured \\
\hline 20 & Male & Afrikaans & Cocaine & No history & Coloured \\
\hline 19 & Male & Afrikaans & Methamphetamine & No history & Coloured \\
\hline 20 & Male & English & Heroin & No history & Sotho \\
\hline 20 & Male & English & Heroin & No history & Coloured \\
\hline 17 & Female & English & Methamphetamine & No history & Coloured \\
\hline 15 & Female & Afrikaans & Methamphetamine & No history & Coloured \\
\hline 15 & Female & Afrikaans & Methamphetamine & Father: Mandrax & Coloured \\
\hline 18 & Female & English & Methamphetamine & No history & White \\
\hline 19 & Male & Afrikaans & Methamphetamine & No history & Coloured \\
\hline 17 & Male & Afrikaans & Methamphetamine & Father: alcohol & Xhosa \\
\hline 18 & Male & Afrikaans & Methamphetamine & Father: alcohol & Coloured \\
\hline 20 & Male & Afrikaans & Methamphetamine & Father: alcohol & White \\
\hline 17 & Male & Afrikaans & Methamphetamine & No history & Coloured \\
\hline 20 & Male & Afrikaans & Alcohol & Both parents: alcohol & Coloured \\
\hline
\end{tabular}

\section{RESEARCH FINDINGS}

The participants in this study gave detailed descriptions of their experiences regarding precipitating factors to their relapses following in-patient treatment and factors that could assist them in preventing further relapses. The ensuing section describes these two themes, and their sub-themes emanating from the data analysis process.

For the purpose of this article, quotations are presented verbatim. However, quotations made in Afrikaans, were translated into English.

\section{Theme 1: $\quad$ Factors precipitating relapsing after treatment among chemically addicted adolescents}

\section{Sub-theme 1: The role of parental support as a precipitating factor to relapses following treatment among adolescents}

The participants' discussions of the effect of parental support, or the lack thereof, illuminated their need for parental guidance and support. The following statements are representative of the contributions of the participants regarding this aspect:

"But when my dad passed away, I had to live up to his reputation. And I guess I could not maintain it, so I cracked."

"So I was supposed to be, uhm, the child in the making. In other words, uhm, so there was a lot of stress on me..."

"But when I get home.... My mom is drunk and her friends are drunk....and my dad works shifts." 
"Like, I didn't have a relationship with my mother and my father. Going to them and say: listen here can't I speak to you about this or that. I always just kept to myself."

"My parents still thought I was on drugs. After a while I thought to myself, is this worth it, because I am not seeing any... I'm not getting anything out of it."

"My mother and my father had problems over me."

Adolescents are placed at risk when they have to enter into life roles before the acquisition of the necessary life skills. (Gouws et al., 2000:63). Poor parent-child communication, substance abuse by the parents, poor family management practices, a lack of parental warmth and trust, lack of parental involvement, dysfunctional discipline, absence of parental limit setting and parents being poor role models furthermore place adolescents at risk (Dimoff, 2007:2; Dodgen \& Shea, 2000:39; Fraser, 2002:122; Gouws et al., 2000:106; National Institute on Drug Abuse, 2006).

The conclusion to these findings is therefore that the parents of chemically addicted adolescents in recovery need guidance regarding expectations and realistic life tasks of adolescents, as well as the role of their examples, discipline and availability. Relapse can also be linked to poor communication between the parents and their children, further illuminating the need for parental guidance and support.

\section{Sub-theme 2: The role of the peer groups as a precipitating factor to relapses following treatment among adolescents}

Apart from the role of parental support, the participants also identified the role of the peer group as a precipitating factor in relapsing, for instance in the following statement:

"I didn't have friends. I got bullied a lot, so uhm...."

The literature highlights two theories, namely, that if the family fails to give acceptance to the adolescent, the adolescent will turn to other means in order to meet this need, and on the other hand that adolescents have a powerful need to spend more time with their peers and less time with their families. On the one hand, the peer group in adolescence provides support and a reference to develop norms and recreation, but on the other hand, peers also strongly influence the adolescent's decision to revert back to drug abuse (Bezuidenhout \& Joubert, 2003:66; Erikson in McCoy et al., 1996:47; McWhirter et al., 2004:119).

Consistent with the characteristics of adolescence, as described in the literature, the participants referred to the distress caused by tension in their relationship with their peer group. Regarding peer pressure and the lack of supportive peer contacts, adolescents in recovery from drug addiction need to be able to form supportive friendships with peers and to be able to have healthy interaction with peers, in order complete the adolescent life tasks. This area needs to be addressed during their adaptation to a new, sober life after treatment.

\section{Sub-theme 3: The role of feelings as a precipitating factor to relapses following treatment among adolescents}

The aforementioned lack of support from parents and peers is related to the emotional precipitating factors to the relapses of the participants.

The statements by the participants regarding positive emotional experiences following treatment are linked to the value of the experience of mastering (Brendtro, Brokenleg \& Von Bockern, 2002:43-60). The following statement describes an experience of mastering sobriety, 
and accentuates the joy it created, thus supporting the description of positive feelings regarding sobriety after treatment in relation to mastering.

"That time meant something for me. And it is nogal nice to be without drugs."

On the other hand, in line with the statements by the participants, the research indicates that drugs provide the adolescent with an opportunity to escape from emotional problems (Mans, 2000:10).

"I felt worst than I did on drugs, so I used to cry... Why me."

"During that time, my uncle raped me, and my mommy she did not want to believe me."

"And you know, worldly stuff, and I thought it would make me happy, but it never worked."

"I would take people's phones and I used to sell it and the thoughts of it...that was something that made me relapsed. I felt really bad."

This sub-theme indicates that adolescents need to address painful emotions, after they leave treatment programmes, and that the fact that they do not learn how to deal with these emotions, and receive no support in this regard, leads to relapses.

\section{Sub-theme 4: The role of reasoning as a precipitating factor to relapses following treatment among adolescents}

The participants referred to the impact of reasoning as another precipitating factor to their relapses through the following responses:

"It was almost as if I already accepted that I will not drug again, but then my mind started telling me to take it again.."

"I only stopped because my parents found out."

"I knew what it meant if I should start again. Problems will come back."

Precipitating factors in relapsing after treatment for chemical addiction are frequent exposure to high-risk situations, physical or psychological reminders, and recurrent thoughts of the past. Arousal becomes a motivational force in order to maintain homeostasis (Grieve, Van Deventer \& Mojapelo-Batka, 2005:176-177). The fact that the participants to this study did not have a replacement for arousal, could therefore contribute to the continued thoughts of missing the drug of choice, and therefore contributed to relapsing.

An internal locus of motivation is needed to enhance the positive reaction to treatment for chemical addiction. With regard to reasoning, the participants noted that knowledge did not prevent them from relapsing, and that the relapses served as confirmation of their addiction. Therefore, they learned from their relapses, but not from the knowledge obtained during the treatment. However, it should be considered that the knowledge enhanced their ability to learn from their relapses (Gorski, 2001:3; Stoppard, 2000:7).

\section{Sub-theme 5: The role of continued drug use as a precipitating factor to relapses following treatment among adolescents}

The participants reflected on the impact of the fact that they did not remain abstinent after first treatments and their efforts to recover from their addiction. They showed insight regarding the role this played in their relapses. The followings statements are representative of the findings regarding this sub-theme:

"I was doing it [referring to drugs] underground every now and then, socially, you know." 
"I did not know that dagga was still a problem, you see? I never stopped with the dagga."

Adhering to abstinence is seen as the long-term goal of recovery, and should therefore be seen as an important aspect in aftercare services (Fisher \& Harrison, 2005:188; Gorski, 2001:2; Malhotra, Basu \& Guptra, 2007:1).

\section{Sub-theme 6: The role of the lack of life skills as a precipitating factor to relapses following treatment among adolescents}

In addition, the participants to this study indicated that they did not have a plan regarding making positive changes in their lives after their first treatments.

"I stayed in the house the whole time, and I fought it. But by Friday I decided I can't take it in any longer. I had to get out of the house."

"I was bored and all that came to mind was just tik."

It was therefore concluded that the participants were not equipped with life skills to create a new lifestyle, when they completed their first treatments. Life skills, including anger management, refusal skills and relaxation, will support the addicted person in his/ her effort to prevent relapse and to adapt to a sober lifestyle (Dodgen \& Shea, 2000:119; Fisher \& Harrison, 2005:162).

\section{Sub-theme 7: The role of physical factors as a precipitating factor to relapses following treatment among adolescents}

The participants also referred to physical factors as a precipitating factor to their relapses. Painful withdrawal symptoms are part of drug addiction, and were identified by the participants as a factor precipitating their relapses.

"It was horrible, because I lied down and my collarbone ached."

"I really did not plan to go back, but when you have that craving....."

A relapse occurs as the addicted person is seeking to relieve physical and emotional cravings (Edmonds \& Wilcocks, 1994:59; Velasquez, Maurer, Crouch, \& DiClemente, 2001:177). It is therefore concluded that chemically addicted persons should be taught skills to deal with cravings and physical discomfort associated with withdrawal, as part of relapse prevention.

On the other hand, one participant reported an improvement in sleeping and eating patterns during the period prior to his relapse, and related it to a positive feeling. This experience is also linked to the value of mastering, relating it to mastering the skill of healthy living, and contributing to a positive emotional experience.

\section{Sub-theme 8: The role of social factors as a precipitating factor to relapses following treatment among adolescents}

Concluding this theme, the participants showed frustration regarding their environments while discussing precipitating factors to their relapses.

"As I walked down the road people said here comes the tikkop and they shut the doors"

“Drugs are bad at school, but the teachers don't know what's going on."

"Where I come from all the young people use drugs."

"It's difficult to stay sober. To see how your friends use drugs." 
Tolerance for drug use in the community, availability, and high crime rates put the chemically addicted adolescent at risk (Fisher \& Harrison, 2005:58; Grieve et al., 2005:177). Therefore, chemically addicted adolescents who receive treatment are placed in high-risk situations when they return home after treatment, if drug use is tolerated, and drugs are available in their immediate environments. When planning aftercare services to chemically addicted adolescents, it should therefore be taken into consideration that the availability of drugs in the communities, as well as tolerance of drug use, harm the efforts to support these adolescents, as the exposure can lead to cravings, which will lead to relapses.

\section{Theme 2: The adolescents' experiences of factors that can assist them in preventing relapses}

\section{Sub-theme 1: The adolescents need social support following treatment}

"NA meetings, because the people there understand you"

"Having a sponsor... to talk to and who understands what I'm going through, just someone to talk to."

\section{"I must continue to do the 12 Steps." [Referring to the NA programme]}

The advantages regarding self-help groups such as Narcotics Anonymous are as follows. The self-help groups provide them with role models to assist them in forming new beliefs regarding substance abuse. These groups assist them to form new, healthy, interpersonal relationships and to learn to function in the community. They provide the adolescents with the opportunity to interact socially, and which leads to independent social interactions. They enhance the feeling of belonging and the ability to adjust norms in a positive way, thus addressing the developmental tasks of adolescence. Self-help groups for the family, such as NARANON and Tough Love ensure that the family members understand the addiction, as well as the recovery process (Barr \& Parrett, 2001:26; Brandt \& Delport, 2005:168; Focus Adolescent Services, 2006:6; McLeod, 2003:449; McWhirter et al., 2004:126-127; Mental Health Touches, 2006:6).

In addition, the Circle of Courage is a valuable therapeutic tool in helping chemically addicted adolescents (Brendtro et al., 2002:43-60). The key areas are belonging, mastery, independence, generosity, and mending the broken circle. It gives purpose to their lives, while a loss of purpose will enhance relapse potential. Contributions to their communities by chemically addicted adolescents in recovery, will also contribute to the experience of the self as worthy, and will lead to a sense of achievement and accomplishment, thus enhancing self-efficacy.

"I want to be somebody that people can look up to."

"I will take my friends to the social worker so that they can also come here." [Referring to the treatment programme].

The conclusion drawn from the responses of the participants is that chemically addicted adolescents need social support, as well as enhancement of their self-efficacy through their examples and support to other chemically addicted adolescents in their communities.

Regarding social support, the following statement reflects a participant's thoughts on the role it can play in either relapsing, or staying sober:

"If you want to stay sober you must find new friends, because you can't stop and be with your old friends." 
Changes in the peer group and environment are important aspects of relapse prevention, and the relapsed chemically addicted adolescent should learn to make different choices when choosing friends (McNeece \& DiNito, 1998:218).

Still focusing on the role of social support, one participant referred to positive input from a community member, providing a positive element in his life after treatment, and prior to his relapse:

"I always spoke to the uncle who cut my hair. He used to take drugs and he told my how he stopped."

The conclusion is therefore made that the aftercare services to chemically addicted adolescents should include self-help groups, positive support and acknowledgement from community members, and contact with positive peer groups.

\section{Sub-theme 2: The adolescents need parental support following treatment}

A participant explained that she was able to withstand a relapse while her mother was at home, but relapsed when her mother returned to work. The fact that her mother was home and available assisted her in her efforts to remain sober.

Another participant referred to her mother's example as something that helped her in her efforts to maintain sobriety, through the following statement:

"My mother dances and has fun without using stuff that can poison her body."

The example of the participant's mother gave her hope that she could experience joy without drugs.

Parental interest, understanding, approval, acceptance, trust, guidance and discipline are factors contributing to the adolescents ability to master developmental tasks (Gouws et al., 2000:68; McNeece \& DiNitto, 1998:221).

The participants reported the following needs regarding parental support as part of aftercare services. They need contact with someone with whom they can discuss stress and painful feelings regarding their relationships with their parents. They asked that their parents should be able to trust them again, and to support them in their efforts to remain sober. One participant specifically referred to the need that his parents should learn to help him to learn new life skills. Two other participants referred to their need to experience love and care from their parents, as part of prevention of further relapses.

The researcher concludes that aftercare services should include parental guidance and parental involvement in therapy during aftercare services to chemically addicted adolescents.

\section{Sub-theme 3: The adolescents need a different lifestyle and life skills following treatment}

Continuing with the theme of factors that can assist chemically addicted adolescents in relapse prevention, the value of a healthy lifestyle to increase self-efficacy must be noted. A change of lifestyle means that a more productive lifestyle should be adopted, to ensure improved quality of life. In order to adjust their lifestyle, life skills are needed to empower relapsed chemically addicted adolescents (Malhotra et al., 2007:1; Van Niekerk \& Prins, 2001:77).

"We [referring to chemically addicted adolescents in recovery who are trying to remain sober] need something to keep our minds off the drugs. Like a place that when you go there you know, ok, when I go there I'm safe. Something else than the police station or the hospital." 
Participants referred to being busy, therefore constructive time management, involvement in church activities, employment, having a sober girlfriend, and participation in sport, were regarded as key areas of positive efforts to maintain sobriety. The participants showed an awareness that their lifestyles did not support their efforts to abstain from drug use. They emphasised at length the importance of change, in order to empower them to withstand the temptations of the drug sub-culture. One participant requested safe places to spend time with sober peers. Three participants continued with this line of thought, and referred to sport activities, outdoor outings and fun days.

The conclusion is therefore made that chemically addicted adolescents should be supported to master the following areas, in order to develop skills to prevent further relapses: guidance regarding education and employment, budgeting, social skills, music, activities to divert the attention away from drugs and the drug sub-culture, and time management.

\section{Sub-theme 4: The adolescents need therapeutic input following treatment}

"Like having an open door, like a passage way, where you are walking through towards your goal. And suppose you just make pit stops here and there for encouragement."

"I could have gone to those places [referring to NA] but if I like knew, or like had more information about the stuff. “

"I need to accept that the world does not revolve around me."

"How to deal with the cravings."

"To try and find the root....the cause of the problems. Small things, that I thought it can't be that that made me go to drugs...it can."

"To become calm, it makes it easier to think."

The aforementioned statements express the participants' views regarding the need for therapeutic support. In addition, therapeutic services should focus on the four primary goals in recovery, namely recognition of the addiction, recognition of need for abstinence, recognition of the importance of a recovery programme, and the diagnosis of other problems that can lead to relapse (Fisher \& Harrison, 2005:155).

Therefore, chemically addicted adolescents should learn to understand themselves, in order to understand the motives behind their behaviour, and to move toward positive change. Therapy, as part of aftercare services, should be available, and focused on information and referrals, family therapy, skills to deal with cravings, forming of new perceptions, and the development of life skills. In conclusion to the aforementioned identified therapeutic needs, the literature emphasises the importance of maintaining change in behaviour and perceptions, as part of the focus of therapy to chemically addicted adolescents (Lewis, Dana \& Blevins, 2002:105).

\section{Sub-theme 5: The adolescents need spiritual support following treatment}

The participants continued to discuss their experiences of factors that could assist them in preventing further relapses, and emphasised spiritual needs as an important aspect to be addressed in relapse prevention.

"I gave my heart to the Lord and there is just something that I feel there is lots of pressure that came off me and I feel more relaxed."

"Pray and the cravings will go away." 
"The church. I will join the youth group. I have to be with young people."

Addressing the spiritual needs of the addicted person is part of total recovery from the addiction, and spirituality gives the adolescent hope and confidence (Gouws et al., 2000:118). The view is that hope derived from spiritual well-being increases the belief that they "can do it", referring to remaining sober.

The researcher therefore concludes that spiritual support, involvement in church activities and spiritual growth are key areas to address when planning aftercare services to the chemically addicted adolescent.

\section{Concluding remarks}

This research enabled the researcher to develop a better understanding of relapsing after treatment, enabling her to identify the aftercare needs of chemically addicted adolescents. Concluding this article, the experiences of chemically addicted adolescents regarding relapsing after treatment focused on the following aspects.

The participants viewed parental and social support as positive elements after treatment, prior to their relapses. However, the participants experienced social, parental and emotional problems that led to relapse. The availability of drugs and the acceptability thereof in the communities were further seen as precipitating factors in relapse. Participants expressed the need for social work intervention, and indicated that a lack of social work input led to relapse. Reasoning needs to be addressed through aftercare services, as this impacts on self-efficacy, motivation to change, and the ability to deal with problems, while maintaining abstinence plays an important role in relapse prevention. In addition, adolescents and their parents need support and guidance to change lifestyles after treatment; the development of life skills is an important element in the ability to change lifestyles. The participants identified time-management and the ability to deal with cravings as important life skills to master as part of relapse prevention. To develop a sense of purpose would be valuable and would contribute to the enhancement of selfefficacy. In addition, the participants explained that knowledge did not prevent them from relapsing, and realised that knowledge should be internalised in order to have an impact on relapse prevention.

- Based on the aforementioned conclusions, the following recommendations to social workers can be made.

- Social workers should coordinate services to chemically addicted adolescents following treatment. Churches, schools, self-help groups, and community leaders should be involved in these services.

- Therapeutic services to chemically addicted adolescents and their parents should include: emotional support; dealing with cravings; life skills; relationships and communication; cognitive therapy to change perceptions and address self-images; development of insight regarding drugs, the damage caused by drugs, and the impact of drug use; and addressing feelings that impact on their recovery.

- Services to chemically addicted adolescents should be available, and these services should focus on the needs expressed by chemically addicted adolescents.

- Social workers should be involved in addressing the issue of availability of drugs and tolerance of drug use in the communities they serve. 
- Social workers should mobilise community activities, and ensure that they are available to chemically addicted adolescents. These activities should ensure that the levels of arousal are maintained through activities that will create joy and excitement.

\section{REFERENCES}

BABBIE, E. \& MOUTON, J. 2001. The practice of social research. Cape Town: Oxford University Press.

BARR, R.D. \& PARRETT, W.H. 2001. Hope fulfilled for at-risk and violent youth: K-12 programs that work $\left(2^{\text {nd }}\right.$ ed). Needham Heights: Allyn and Bacon Publishers.

BARRETT, P.M. \& OLLENDICK, T.H. 2004. Interventions that work with children and adolescents. Prevention and treatment. West Sussex: John Wiley and Sons Ltd.

BEZUIDENHOUT, C. \& JOUBERT, S. 2003. Child and youth misbehavior in South Africa. A holistic view. Pretoria: Van Schaik Publishers.

BRANDT, C.J. \& DELPORT, C.S.L. 2005. Theories of adolescent substance use and abuse. Professional Journal for Social Work, 41(2):163-175.

BRENDTRO, L.K.; BROKENLEG, M. \& VON BOCKERN, S. 2002. Reclaiming youth at risk. Our hope for the future (rev ed). Indiana: Indiana National Education Service.

BUDDY, T. 2003. Addiction relapse similar to other chronic diseases. Available: http://alcoholism.about.com/cs/relapse/a/blcaron030804.htm.

BUTTS, J.A. \& ROMAN, J. 2004. Juvenile drug courts and teen substance abuse. Washington: The Urban Institute Press.

CHERRY, A.L. 2000. A research primer for the helping professions. Methods, statistics and writing. Belmont: Brooks/Cole Publishing Company.

CRESWELL, J.W. 2003. Research design: qualitative, quantitative and mixed approaches $\left(2^{\text {nd }}\right.$ ed). Thousand Oaks: Sage Publishers.

DE VOS, A.S., STRYDOM, H., FOUCHÉ, C.B. \& DELPORT, C.S.L. 2002. Research at grass roots. For the social sciences and human service professions $\left(2^{\text {nd }}\right.$ ed $)$. Pretoria: Van Schaik Publishers.

DICK, B. 2000. Grounded theory. Available: http://www.scu.edu.au/schools/gcm/ar/arp/grounded.html.

DIMOFF, T. 2007. How substance abuse starts. Available: http://www.sacsconsulting.com/book/chapter 1.htm.

DODGEN, C.E. \& SHEA, W.M. 2000. Substance use disorders. Assessment and treatment. San Diego: Academic Press.

EDMONDS, L. \& WILCOCKS, L. 1994. Teen drug scene in South Africa. Pinegowrie: Atlas Litho.

FISHER, G.L. \& HARRISON, T.C. 2005. Substance abuse ( $3^{\text {rd }}$ ed). Boston: Pearson Education.

FOCUS ADOLESCENT SERVICES. 2006. Teenagers and drugs. Available: http://www.focusas.com/SubstanceAbuse.html. 
FRASER, M.W. 2002. Risk and resilience in childhood. An ecological perspective. Washington: NASW Press.

GOODWIN, D.W. 2000. Alcoholism: the facts ( $3^{\text {rd }}$ ed). Oxford: Oxford University Press.

GORDON, S.M. 2003. Relapse - removing the taboos on the topic and promoting honest efforts to address it. Wernersville: Caron Foundation.

GORSKI, T.T. \& MILLER, M. 1982. Counseling for relapse prevention. Independence. Herald House/Independence Press. Aspen, Colorado.

GORSKI, T.T. 2001. Adolescent relapse prevention. Available:

http://www.tgorski_articles/adolescent.

GOSSOP, M. 1998. Living with drugs ( $4^{\text {th }}$ ed). Vermont: Ashgate Publishing Company.

GOUWS, E., KRUGER, N. \& BURGER, S. 2000. The adolescent $\left(2^{\text {nd }}\right.$ ed). Sandown: Heineman Publishers.

GRIEVE, K., VAN DEVENTER, V. \& MOJAPELO-BATKA, M. 2005. A student's a-z of psychology. Landsdowne: Juta and Company Limited.

HEALTH SYSTEMS TRUST. 3 July 2002. South Africa: drug use flourishing (Online). Available: http://www.hst.org.za/news.

KREFTING, L. 1991. Rigor in qualitative research: The assessment of trustworthiness. American Journal of Occupational Therapy, 45(3):214-222.

LEWIS, J.A., DANA, R.Q. \& BLEVINS, G.A. 2002. Substance abuse counseling. Pacific Grove: Brooks/Cole Publishing Company.

LOUW, D.A., VAN EDEN, D.M. \& LOUW, A.E. 2001. Human development $\left(2^{\text {nd }}\right.$ ed). Cape Town: Kagiso Tertiary Publishers.

MALHOTRA, A., BASU, D. \& GUPTRA, N. 2007. Psychosocial treatment of substance use disorders in adolescents. JIACAM, 1(1).

MANS, P. 2000. Dwelms: word straatwys oor dwelms. Cape Town: Lux Verbi.

McCOY, C.B., METCH, L.R. \& INCIARDI, J.A. 1996. Intervening with drug-involved youth. Thousand Oaks: Sage Publishers.

McLEOD, J. 2003. An introduction to counseling ( $3^{\text {rd }}$ ed). Berkshire: Open University Press.

McNEECE, C.A. \& DiNITO, D.M. 1998. Chemical dependency. A systems approach $\left(2^{\text {nd }}\right.$ ed). Boston: Allyn and Bacon Publishers.

McWHIRTER, J.J., McWHIRTER, B.T., McWHIRTER, E.H. \& McWHIRTER, R.J. 2004. At-risk youth. A comprehensive response $\left(3^{\text {rd }}\right.$ ed). Canada: Brooks/Cole Publishing Company.

MENTAL HEALTH TOUCHES. 2006. Getting the facts about adolescent substance abuse and treatment. Available: http://www.athealth.com/Consumer/adolescentsufacts.html.

MINISTRY FOR WELFARE AND POPULATION DEVELOPMENT. 1997. White Paper for Social Welfare. Pretoria: Government Printer.

NATIONAL INSTITUTE ON DRUG ABUSE, 2006. Director's report. Available: http://www.drugabuse.gov/DirReports/DirRep904/DirectorReport9.html. 
NOYOO, N., PATEL, L. \& LOFFELL, J. 2006. The human development situation of Johannesburg's youth. Professional Journal for Social Work, 42(1):93-100.

PROMULGATION OF NATIONAL POLICY ON THE MANAGEMENT OF DRUG ABUSE BY LEARNERS IN PUBLIC AND INDEPENDENT SCHOOLS AND FURTHER EDUCATION AND TRAINING INSTITUTIONS. 2006. Government Gazette. Vol. 450 (13 December 2002). Pretoria: Government Printer.

RUBIN, A. \& BABBIE, E. 1997. Research methods for social work $\left(3^{\text {rd }}\right.$ ed). Pacific Grove: Brooks/Cole Publishing Company.

SILVERMAN, D. 2000. Doing qualitative research: a practical handbook. London: Sage Publications.

SMITH, M. 2006. Medpage. Pure “ice" fuelling Methamphetamine epidemic. Available: http://www.medpagetoday.com. [Retrieved: 24 May 2006].

SOUTH AFRICAN COMMUNITY EPIDEMIOLOGY NETWORK ON DRUG USE. 2005. News update. December. Medical Research Council, South Africa.

SOUTH AFRICAN POLICE SERVICE. 2006. Crime Analysis. March.

STOPPARD, M. 2000. Dwelm Info Lêer. London: Dorling Kindersley Publishers.

TERBLANCHE, S.S. \& VENTER, D. 1999. Drug abuse amongst high school pupils. Social Work/Maatskaplike Werk, 35(2):161-178.

VAN NIEKERK, E. \& PRINS, A. 2001. Counseling in South Africa. A youth perspective. Sandown: Heinemann Publishers.

VELASQUEZ, M.M., MAURER, G.G., CROUCH, C. \& DiCLEMENTE, C.C. 2001. Group treatment for substance abuse. A stages-of-change therapy manual. New York: Guilford Press.

WALLIMAN, N. 2001. Your research project. Thousand Oaks: Sage Publications.

YEDIGIS, B.L. \& WEINBACH, R.W. 1996. Research methods for social workers ( $2^{\text {nd }}$ ed). London: Allyn \& Bacon.

YOUTH AT THE UNITED NATIONS. 2006. United Nations: World Programme of Action for Youth (Online). Available: http://www.un.org/esa/socdev/unyin/wpaydrug.html.

ZULU, X. 2006. Health Systems Trust. Youth turns to drugs as sales at schools soar. 17 March. Available: http://www.hst.org.za/news.

Mrs Marichen van der Westhuizen, Lecturer, Huguenot College, Wellington, South Africa.

Dr Marianna de Jager, Lecturer, University of Western Cape, Bellville, South Africa. 